\title{
Human Resource Management in Health Care Sector a Conceptual Study
}

\author{
K.Naga Sundari ${ }^{1}$, Prof. V. Narasimha Rao ${ }^{2}$ \\ ${ }^{I}$ Research Scholar, Krishna University, Machilipatnam, AP \\ ${ }^{2}$ Director, PG Studies, ANR College, Gudivada, AP
}

\begin{abstract}
Human Resources are considered as an important element in service industry in general and in specific in health care sector. As there is an evidence of increase in income levels of the people in the society, and the entry of state-of-art technology to provide quality health care has brought an enormous awareness among customers to opt for a better health care. In the recent years there is a rise in the competition among the health care providers to provide quality treatment to their clients, India is rising as a medical hub and has become a favorite destination for many middle-easts and developing economies.The purpose of this study is to understand the importance of human resources in this sector. An extensive review of literature is done, recommendations were drawn to enhance quality of health care professionals, which may in turn lead to customer satisfaction.
\end{abstract}

Key words: state-of-art technology, developing economies, health care, health care professionals

\section{Introduction}

Human resource is considered as the epicenter of the health care industry and believed that human resources play the most critical and significant role in achieving organizational goals and success. Human capital has been recognized as the organization's life blood, which needs to be developed continuously keeping pace with the development in all other areas of today's dynamic work environment.

A knowledgeable workforce, one that is both highly skilled in a particular occupation and also exhibits flexibility, is seen as the most important human capital resources for the development of a county.

In the emerging global market place, human capital will matter more to enterprises than physical capital, and human capabilities will determine the value of enterprise (ILO, 2000). In today's modern era, the quantity of employment cannot be divorced from its quality.

\section{Objective}

To understand the conceptual framework of HRM practices in Health Care Sector and its impact on health care services.

\section{Data Collection}

This paper presents an extensive review of literature. It explains the present on going research work in HRM in health care sector. Data is collected through secondary source (i.e), from journals magazines etc. Through this study the researcher tries to understand and assess the role of HRM on the quality of health care services.

\section{Review Of Literature}

Adwan (2008) with his study entitled "The Reality of workforce planning in the non governmental health sector in the provinces of Gaza", showed that institutions do not engagen workers in the HR planning process and lack clarity as well as professional experience in manpower planning and top management support, The study recommended to prepare plans and clear vision in a professional and systematic approach to develop human resources and the study alos urged to create a separate department for personal affairs, involve employees and also to use external expertise for determining the HR needs in health institutions.

Mukhaimar and Taamenah(2004) with their studies entitled "Recent trends for the hospital management : Concepts and applications", the researcher found that although the hospital prepared quality plans and organizational structure s according to scientific methods, the hospital management found that they failed in achieving objectives due to failoures in routing functions. The study concluded that the function of a director of the hospital not only to provide diagnostic and treatment services but also to pay attention to the feelings of various categories of workers in the hospital i.e. doctors, technicians and administrators and understand the conditions of work. Al Kudhat Mohammed (2004), with his study entitled "Methods of selecting staff in king Abdullah the light of technological developments", the main findings of this study is that there is a positive relationship between personality traits of those who have been recruited and technology employed in the 
hospital, It also revealed that there is an impact of high technology in the analysis and design of work, job classification and the nature of work. Valverde and Ryan (2006) in their research entitled "Distributing HRM responsibilities : a classification of organizations" The aim of the study was to bring into light that HRM is not the sole responsibility of HR Departments but also all the agents inside and outside the organizations, such as top and line managers and HRM service providers. The researcher examined how organisations distribute HRM activities and responsibilities among these agents. The findings of this study showed that the HR model adopted by an organization may not be contextually determined but instead it is a matter of corporate choice, companies actually choose what type of model of HRM they want and distribute responsibilities accordingly. It was concluded that large number of organizations have proved very useful in identifying a wide range of behaviours in the distribution of HR responsibilities.

Rosemary Lucas (2002) in her study entitled "Fragments of HRM in hospitality? Evidence from 1998 workplace employee relations survey", were the existence of strict centralization in most hospitals, which limits the development of the work of individuals and nurses, lack of new development of work in the event of performance failure and failure to protect the rights of workers and individuals in hospitals during transformation process in health sector.

A study entitled "The filling in the Sandwich : HRM an middle managers in the health sector", Mc Conville and Holden (2003), the study showed the central role of line managers in implementing HRM, is widely acknowledged . A case-study in two Trust hospitals, the study demonstrates that middle -line managers, positioned between the service's decision making bodies have a bearing on the consequences of the change process. With growing work loads, altered expectsations have enhanced the tensions and role conflict inherent to their position. The study found that the perception of line managers are under resourced and found lack of time to manage their staff effectively. Staff is being more closely managed, changing nature of personnel management throughout the service have regained responsibility for many aspects of HRM.

Astudy entitled "Human resource management and performance in healthcare organizations", Harris et al.(2007), this study compared the evidence from a range of reviews concerned with the links between HRM and performance. The study reviewed diverse literature and to derive HR implications for the health care researchers, policy makers and managers. The study also found the relationship between a range of HRM practices, policies, systems and performance. The study concluded that tailoring of HR practices to suit local circumstances, potential impact of any HR practice on performance and HR outcomes such as motivation and satisfaction.

A study entitled "Managing professionals: exploring the role of the hospital function", McDermott and Keating (2011), the objective of the study was to examine the role of HR function in the management of professional and non professional staff in hospital sector. The study finds that in two of the three cases the HR function provides services to non-professional work force. However, the effective and strategic management of professionals is undertaken in third case, without a professional HR function. The study suggests that HRM as the "management of people and work". As a result, a focus on formal HRM structures in hospital organizations is insufficient to capture people particularly strategically valuable workforce groups and work are managed.

\section{Recommendations}

The review of previous literatures that cover the field of HRM in health care sector shows that the sector requires improvement in various activities such as Recruitment, Performance Management, Training and Development and Job satisfaction.

The study sets the following recommendations

1. To develop an effective recruitment policy for hiring health care professionals.

2. Continuous training and development of personnel is needed to gain patient satisfaction and provide better services to the patients.

3. The health care organizations must develop a systematic Performance Management System and continuously assess performance of its professionals.

4. The job enlargement of professionals makes them more responsible, motivated and committed to their profession.

\section{Conclusion}

The management of HR enables the efficient delivery of health care services to the patients and achieve patient satisfaction. Organisations success depends on the successful implementation of effective HRM practices. The top management in hospitals should have a clear vision and formulate strategies. The objectives of the organizations are to be made clear to all the levels of the employees. More emphasis on periodic performance reviews and training and development of doctors, nurses and paramedics would improve quality of health care services. 


\section{References}

[1]. Jamal, K. Adwan, A(2006), The reality of workforce Planning in the health sector hospitals the non-governmental sector in the province of Gaza.

[2]. Mukhaimar, M \&Taamenh, J.(2004). Recent trends for the hospital management: concepts and applications.

[3]. Al Khudat, M.(2004), Staff selection methods in the King Abdullah Hospital founder in light of technological developments. Unpublished Master thesis, Yarmouk University, Irbid, Jordan.

[4]. Valverde, M\&Ryan G. (2006), Distributing HRM responsibilities : A classification of organizations Universitat Rovira Virgili, Department of Business, Avinguda Universitat, Tarrangona, Spain, Vol.35.No.6, Emerald Group Publishing Ltd.

[5]. Lucas, R (2002). Fragments of HRM in hospitality? Evidence from the 1998 workplace employee relations survey. International Journal of Contemporary Hospitality Management

[6]. Mc Conville, T(2003). The filling in the Sandwich. Hrm and middle managers in the health sector, University of Plymouth Business school, Plymouth, UK, and Len Holden, Vol.28.No.5/6, MCB University Press.

[7]. Harris,C., Cortvriend, P. \& Hyde, P (2007), Human Resource Management and Performance in health care organizations, University of Manchester, Manchester, UK. Journal of Health and Organiation and management 21(4/5).

[8]. Keating. M(2011). Managing Professionals: Exploring the role of the hospitqal HR function Aoife Mc Dermott, Cardiff University Business School, Cardiff, UK.Journal of Health organization and management 25(6) 